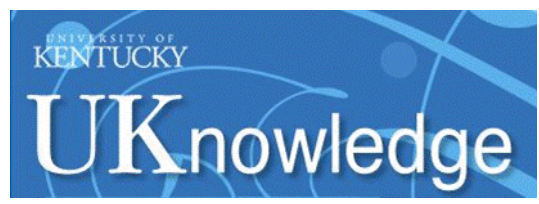

University of Kentucky

UKnowledge

6-2009

\title{
Cancer Information-Seeking Experiences: The Implications of Hispanic Ethnicity and Spanish Language
}

\author{
Robin C. Vanderpool \\ University of Kentucky, robin@kcr.uky.edu \\ Julie Kornfeld \\ University of Miami \\ Lila Finney Rutten \\ National Cancer Institute \\ Linda Squiers \\ National Cancer Institute
}

Follow this and additional works at: https://uknowledge.uky.edu/healthbehavior_facpub

Part of the Public Health Commons

Right click to open a feedback form in a new tab to let us know how this document benefits you.

\section{Repository Citation}

Vanderpool, Robin C.; Kornfeld, Julie; Finney Rutten, Lila; and Squiers, Linda, "Cancer Information-Seeking Experiences: The Implications of Hispanic Ethnicity and Spanish Language" (2009). Health, Behavior \& Society Faculty Publications. 7.

https://uknowledge.uky.edu/healthbehavior_facpub/7

This Article is brought to you for free and open access by the Health, Behavior \& Society at UKnowledge. It has been accepted for inclusion in Health, Behavior \& Society Faculty Publications by an authorized administrator of UKnowledge. For more information, please contact UKnowledge@lsv.uky.edu. 


\title{
Cancer Information-Seeking Experiences: The Implications of Hispanic Ethnicity and Spanish Language
}

\author{
Digital Object Identifier (DOI) \\ http://dx.doi.org/10.1080/08858190902854772 \\ Notes/Citation Information \\ Published in Journal of Cancer Education, v. 24, issue 2, p. 141-147. \\ (C) 2009 AACE and EACE
}

The document available for download is the authors' post-peer-review final draft of the article. 


\title{
Cancer Information-Seeking Experiences: The Implications of Hispanic Ethnicity and Spanish Language
}

\author{
ROBIN C. VANDERPOOL, DRPH, CHES, JULIE KORNFELD, MPH, LILA FINNEY RUTTEN, \\ PHD, MPH, and LINDA SQUIERS, PHD \\ Mid South Region Cancer Information Service, University of Kentucky Markey Cancer Control \\ Program (RCV); Coastal Region Cancer Information Service, Sylvester Comprehensive Cancer \\ Center, University of Miami Miller School of Medicine (JK); Health Communication and \\ Informatics Research Branch, National Cancer Institute, National Institutes of Health (LFR); and \\ The Cancer Information Service, National Cancer Institute, National Institute of Health (LS)
}

\begin{abstract}
Background-Strategies to support cancer information-seeking among Hispanics are needed.

Methods-We analyzed data from the 2005 Health Information National Trends Survey (HINTS) to explore cancer information-seeking experiences among respondents according to ethnicity and language of interview.
\end{abstract}

Results-Over $80 \%$ of Spanish-speaking Hispanics had never looked for cancer information. Compared to English-speaking respondents, Spanish-speaking Hispanics who sought cancer information indicated their search took a lot of effort (67\%), was hard to understand (54\%), and frustrating (42\%). Spanish-speaking Hispanics noted minimal confidence in obtaining cancer information.

Conclusions-Language and cultural differences must be considered in the design, implementation, and dissemination of cancer information.

\begin{abstract}
Hispanic Americans are the largest and fastest growing minority population in the United States. As of July 1, 2006, the US Census estimated over 44 million individuals self-identify as Hispanic. ${ }^{1}$ It is increasingly recognized that compared to non-Hispanics, Hispanic populations are more likely to encounter barriers to optimal health including access to care, lack of health insurance and regular source of medical care, limited finances, and lower education and literacy levels. ${ }^{2-5}$ These barriers, in turn, contribute to health disparities, particularly related to cancer, the second leading cause of death among Hispanics.

In 2006, approximately 82,000 new cancer cases were diagnosed among Hispanic men and women in the United States. ${ }^{6}$ During the same time period, over 23,000 Hispanics died from cancer. ${ }^{6}$ Although Hispanics experience lower incidence and mortality rates for the most common cancers such as breast, prostate, colon and rectum, and lung, they have higher rates for cervix, stomach, liver, and gallbladder cancers when compared to non-Hispanics. ${ }^{4,6}$ In a study examining racial and ethnic differences in women diagnosed with invasive cervical cancer from 1992-2003, Hispanic whites had the highest age adjusted incidence rate of
\end{abstract}

Copyright $\odot$ AACE and EACE

Address correspondence and reprint requests to: Robin C. Vanderpool, Mid South Cancer Information Service, University of Kentucky Markey Cancer Control Program, 2365 Harrodsburg Road, Suite A230, Lexington, KY 40504; phone: (859) 219-9063; fax: (859) 219-2276; < robin@ cis.uky.edu>.

Presented as a poster at the National Cancer Institute's 2007 Health Information National Trends Survey (HINTS) Data Users Conference, Pasadena, California, May 4, 2007. 
invasive cervical cancer $(24.2 / 100,000)$ compared to other racial/ethnic groups. ${ }^{7}$ Research has also documented that Hispanic men and women do not regularly participate in cancer screening, which may lead to cancers being diagnosed at later, more advanced stages, leading to lower survival rates. Compared to non-Hispanic women, lower usage of Pap tests, mammography, and clinical breast exams has been documented among Hispanic women. 5,6 Adherence to recommended screening guidelines for fecal occult blood tests or lower endoscopic exams is also lower among Hispanics compared to non-Hispanics. ${ }^{4,6}$

In addition to disparities in disease burden, there are continuing gaps in access to health information among low income and minority populations in the United States. There is a growing body of research that indicates that different ethnic groups experience varied access to health-related information, leading to gaps in knowledge and widening health disparities. ${ }^{8}$ Accordingly, this knowledge gap hypothesis suggests people of higher socioeconomic status have enhanced information access and information-seeking skills that place them in a favorable position to obtain information and make informed medical decisions across the spectrum of health and illness. ${ }^{9,10}$ Of all racial and ethnic groups, low-income Hispanic populations have been documented to be the least likely to have health insurance and the most likely to encounter barriers accessing care. ${ }^{4,11}$ Research to date suggests Hispanics tend to utilize television, family and friendship networks, interpersonal connections with health care providers, and ethnically targeted media including TV and small community newspapers as sources for health information. ${ }^{12-16}$ However, little attention has been paid to the experience of information seeking among this growing population, particularly among those who are recent immigrants with limited English proficiency.

The specific aims of our study were to explore differences in the experience of cancer information-seeking among Hispanics who responded to the 2005 National Cancer Institute's (NCI) Health Information National Trends Survey (HINTS) in English, Hispanics who responded in Spanish, and non-Hispanic respondents who completed the survey in English. Although language fluency is but 1 of many factors that may impact health outcomes among Hispanics, it is often used as a proxy for cultural orientation. ${ }^{17-19}$ Spanishspeaking Hispanics can be linguistically isolated, less acculturated, or possess limited English proficiency when compared to English-speaking Hispanics and non-

Hispanics. ${ }^{18,20-22}$ As such, Hispanics may shoulder excessive barriers to accessing and communicating with a primarily English-language health care system, receiving quality care, participating in appropriate cancer prevention and screenings activities, and obtaining relevant and practical cancer information. ${ }^{2,5,20,21}$ The US Census reports almost $11 \%$ of the US population, or 28.1 million people, speak Spanish as their primary language, and almost half (13.8 million) of this Spanish-speaking population speaks English less than "very well." 23 These data indicate a large segment of the Hispanic population may be at risk for disparities in health knowledge and adverse health outcomes across the cancer continuum. ${ }^{2,10}$

\section{MATERIALS AND METHODS}

\section{Data Collection, Response Rates, and Sample}

Data for this analysis are from the NCI's 2005 HINTS. Data for HINTS 2005 was collected from February 2005 through August 2005. The survey design was a list assisted, random digit dial of all telephone exchanges in the United States administered by trained interviewers to a representative sample of US households. One adult aged 18 or older was selected during a household screener for extended interview $(n=5586)$. Respondents were given the choice to complete the survey in English or in Spanish. The response rate for the household screener was $34.0 \%$, and the response rate for the extended interview was $61.3 \%$. Further information about the sample and sampling design are reported elsewhere 
(http://www.cancercontrol.cancer.gov/hints/-see HINTS 2005 Final Report). The HINTS 2005 survey was granted an exempt status by the NCI's Office of Human Subjects Research Internal Review Board (IRB) and by the IRB of the organization contracted to conduct the HINTS survey, Westat.

\section{Sociodemographic Characteristics}

All analyses were stratified by language of interview (Spanish or English) and ethnicity (Hispanic or non-Hispanic). Ethnicity was assessed according to the Office of Management and Budget standards. ${ }^{24}$ Our analyses included the following sociodemographic characteristics: gender, age, education, household income, location of birth (United States or outside United States), level of comfort speaking English, and number of years residing in the United States.

\section{Information-Seeking Experiences}

Information-seeking experiences were assessed with a series of questions wherein respondents were asked to agree or disagree with the following statements: (1) It took a lot of effort to get the information you needed; (2) You felt frustrated during your search for the information; (3) You were concerned about the quality of the information; and (4) The information you found was too hard to understand. Respondents were also asked to rate their confidence in future information seeking: Overall, how confident are you that you could get advice or information about cancer if you needed it?

\section{Analyses}

Analyses were conducted to account for the complex survey design of HINTS 2005 using SAS-callable SUDAAN Version 9.0. ${ }^{25}$ Estimates were weighted to be representative of the US population. Chi-square tests were conducted to analyze bivariate associations of sociodemographic variables with language spoken during interview and self-reported ethnicity as well as cancer information-seeking experiences. Multivariate logistic regression analyses were conducted to assess independent associations.

\section{RESULTS}

Weighted frequencies and means for sociodemographic characteristics are shown in Table 1. A total of 5344 HINTS respondents had valid responses for ethnicity; among this subpopulation, $90.8 \%$ self-identified as non-Hispanic $(\mathrm{n}=4850)$ and $9.2 \%$ as Hispanic $(\mathrm{n}=$ 494). Of the Hispanic respondents, $46.2 \%$ completed the survey in English $(n=228$; hereafter referred to as English-speaking Hispanic respondents), whereas $53.8 \%$ of Hispanic respondents completed the survey in Spanish $(n=266$; hereafter referred to as Spanishspeaking Hispanic respondents).

Compared to non-Hispanics respondents (47.1\%), a significantly higher percentage of English-speaking Hispanic respondents (54.9\%) and Spanish-speaking Hispanic respondents (52.0\%) were male. Compared to non-Hispanic respondents (58.3\%), a significantly higher percentage of English-speaking Hispanic respondents (79.4\%) and Spanish-speaking Hispanic respondents $(81.9 \%)$ were under 50 years of age. A significantly greater proportion of Spanish-speaking Hispanic respondents (61.9\%) reported incomes of less than $\$ 25,000$ per year compared to $26.0 \%$ of English-speaking Hispanic respondents and $20.8 \%$ of nonHispanic respondents. Significant differences in level of educational attainment were also found between the 3 groups: Spanish-speaking Hispanic respondents (54.2\%) were significantly more likely to have less than a high school education compared to Englishspeaking Hispanic respondents (19.8\%) and non-Hispanics (10.3\%). Significant differences also were found in the proportion of each group that reported that they were born in the 
United States. Over 90\% of the Spanish-speaking Hispanic respondents were born outside of the United States. A significantly greater proportion (91.4\%) of English-speaking Hispanic respondents reported feeling comfortable speaking English compared to 21.2\% of Spanishspeaking Hispanic respondents and $85.7 \%$ of non-Hispanic respondents. Mean number of years residing in the United States was significantly different across groups: non-Hispanics reported residing in the United States for 45.3 years compared to 34.3 years for Englishspeaking Hispanic respondents and 14.4 years for Spanish-speaking Hispanic respondents.

Related to cancer information seeking, the data reveal non-Hispanics are more likely to seek information (53.2\%) compared to both English-speaking Hispanics (37.1\%) and Spanishspeaking Hispanics (16.7\%). Bivariate associations of cancer information-seeking experiences among those who have sought cancer information, by language spoken and ethnicity, are summarized in Table 2. Results indicate that almost 70\% of Spanish-speaking Hispanic respondents were significantly more likely to agree that their last search for cancer information took a lot of effort compared to $43.3 \%$ of English-speaking Hispanic respondents and $35.6 \%$ of non-Hispanic respondents. Spanish-speaking Hispanic respondents $(54.7 \%)$ were also significantly more likely to agree that the information they found was hard to understand compared to the other 2 groups (24.8\% of English-speaking Hispanics and 22.2\% of non-Hispanics). Although Spanish-speaking Hispanics were more likely than English-speaking Hispanics and non-Hispanics to agree that they found their last search frustrating, the differences between the 3 groups was not statistically significant nor was the difference in the proportion who agreed that they were concerned about the quality of the information they found. Given the low number of Spanish-speaking Hispanic respondents who indicated they had searched for cancer information on the Internet, statistical comparisons between the 3 groups on this variable are unreliable and therefore should be interpreted cautiously.

To determine which variables were independently associated with each of the specific cancer information-seeking experiences and behaviors, 4 logistic regression models were conducted (Table 3). Independent variables for all models included gender, age, education, income, language used in the interview, and number of years in the United States.

The overall model for sought cancer information was significant $\left(\mathrm{F}_{14}=14.93, P<.0001\right)$. Compared to non-Hispanics, English-speaking Hispanics (odds ratio $[\mathrm{OR}]=0.59$, confidence interval $[\mathrm{CI}]=0.38-0.92)$ and Spanish-speaking Hispanics $(\mathrm{OR}=0.25, \mathrm{CI}=$ $0.15-0.43$ ) were significantly less likely to have sought cancer information. Compared to respondents with less than a high school education, respondents who graduated from high school or had some college education $(\mathrm{OR}=2.10, \mathrm{CI}=1.53-2.89)$ and respondents who graduated from college $(\mathrm{OR}=3.38, \mathrm{CI}=2.31-4.95)$ were significantly more likely to have searched for cancer information. Females $(\mathrm{OR}=1.79, \mathrm{CI}=1.46-2.20)$ were significantly more likely to have searched for cancer information than males.

The model for confidence in obtaining cancer information was also significant $\left(\mathrm{F}_{14}=21.54\right.$, $P<.0001)$. Compared to non-Hispanics, Spanish-speaking Hispanics were less likely to feel confident they could obtain cancer information ( $\mathrm{OR}=0.35, \mathrm{CI}=0.22-0.57)$. Compared to respondents earning less than $\$ 25,000$ per year, respondents earning $\$ 50,000$ to $\$ 75,000$ per year $(\mathrm{OR}=1.40 ; \mathrm{CI}=1.01-1.94)$ and respondents earning greater than $\$ 75,000$ per year $(\mathrm{OR}=1.63, \mathrm{CI}=1.21-2.19)$ were more confident they could obtain cancer information. Finally, compared to younger respondents (18-34 years of age), respondents 35 to 49 years of age $(\mathrm{OR}=0.63, \mathrm{CI}=0.47-0.86)$ expressed lower confidence in obtaining cancer information. 
The model examining information-seeking effort (It took a lot of effort ...) was significant $\left(\mathrm{F}_{14}=9.48, P<.0001\right)$. Compared to respondents who were 18 to 34 years of age, those 50 to $64(\mathrm{OR}=2.80, \mathrm{CI}=1.57-4.97)$, those 65 to $74(\mathrm{OR}=3.85, \mathrm{CI}=1.61-9.23)$, and those 75 and older ( $\mathrm{OR}=6.49, \mathrm{CI}=2.38-17.69)$ were significantly more likely to report that their search took a lot of effort. Compared to respondents with less than a high school education, those who were college graduates $(\mathrm{OR}=0.48, \mathrm{CI}=0.25-0.91)$ were less likely to report that their search took a lot of effort. There were no significant differences between nonHispanics, English-speaking Hispanics, or Spanish-speaking Hispanics on reported information-seeking effort.

Finally, the model for difficulty in understanding information (information ... was hard to understand) was significant $\left(\mathrm{F}_{14}=37.90, P<.0001\right)$. Compared to respondents 18 to 34 years of age, all other age groups were significantly more likely to indicate that the information was hard to understand: 35 - to 49 -year-olds ( $\mathrm{OR}=2.03, \mathrm{CI}=1.20-3.46)$; 50 - to 64-year-olds ( $\mathrm{OR}=3.31, \mathrm{CI}=1.48-7.39)$; 65- to 74-year-olds $(\mathrm{OR}=3.17, \mathrm{CI}=1.03-9.73)$; and 75 years of age and older $(\mathrm{OR}=3.97, \mathrm{CI}=1.03-15.36)$. Compared to respondents earning $\$ 25,000$ or less, respondents earning $\$ 50,000$ to 75,000 per year $(\mathrm{OR}=0.63, \mathrm{CI}=$ $0.42-0.93)$ and respondents earning $\$ 75,000$ or more $(\mathrm{OR}=0.54, \mathrm{CI}=0.34-0.86)$ were significantly less likely to report that information was hard to understand.

\section{DISCUSSION}

There are important differences between Hispanics and non-Hispanics related to cancer information-seeking experiences. Overall, when compared to non-Hispanics, both Spanishand English-speaking Hispanics fared worse on sociodemographic measures and were more likely to perceive their cancer information-seeking experiences negatively. Respondents who answered the survey in Spanish demonstrated greater disparities, suggesting that language may also play a role in contributing significantly to cancer health disparities. In the context of what is known about the elevated health risks of Hispanics who have poor access to care and are underinsured, the greater barriers to information seeking identified in our analyses underscore the isolation of this population. Low-income Hispanics in the United States are the least likely to have health insurance and the most likely to meet difficulties in accessing care. ${ }^{4,11,16}$ Our analyses suggest that Hispanics also encounter multiple difficulties and have minimal confidence in accessing health information. Disparities in cancer information-seeking and information access have the potential to negatively shape health knowledge, attitudes, behaviors, and medical decisions and can therefore contribute to disparities in health outcomes. ${ }^{8,26,27}$ Similar to findings by Tortolero-Luna and colleagues $^{28}$, the cancer information-seeking disparities noted in this article suggest that Hispanics, particularly those who responded to the survey in Spanish, may experience multiple challenges and barriers in seeking and interpreting cancer information and in making informed or shared decisions about their health. These information-seeking disparities, combined with known challenges related to communication with providers, health insurance coverage, access to care, and knowledge of available and appropriate health care services, contribute to the inequality in the cancer burden.

\section{Limitations}

Response rates for HINTS 2005 were fairly low; the final response rate for the household screener was $34.0 \%$, and the final response rate for extended interview was $61.3 \%$. However, these rates are comparable to other national telephone surveys and reflect the decreasing trend in response rates for telephone surveys. ${ }^{29}$ HINTS 2005 is not a prospective study; therefore, results of our analyses provide a cross-sectional snapshot of information seeking among Hispanic and non-Hispanic populations. Longitudinal examination of information seeking among sociodemographically defined subgroups would provide 
valuable insight for cancer educators and planners. Although HINTS does ask respondents if they were born in the United States, what year they came to live in the United States, and level of comfort in speaking English, the survey does not currently differentiate Hispanic respondents by country of origin or paternal/maternal country of origin, which would yield additional information related to the varying cultural backgrounds of the survey participants. Last, our reliance on language as a proxy for preferred language may not adequately capture cultural orientation. The authors readily recognize the heterogeneity of the Hispanic population and that health information seeking is a complex and multifaceted behavior influenced by a combination of factors including culture; socioeconomic status; degree of ethnic identity; health literacy, knowledge, attitudes and beliefs; familial involvement; and access to information sources. ${ }^{16,30}$ Nonetheless, this national snapshot does contribute to the growing body of work examining the information-seeking experiences and behaviors of Hispanics in this country and reinforces the need to understand Hispanics' communication behaviors to more effectively support this population in a rapidly evolving and increasingly complex health information environment.

\section{Conclusions and Future Research}

Health planners and practitioners often rely on trusted and established mainstream information sources to reach populations at risk for disease and poor health outcomes. Yet, increasing differences in preferred and trusted sources for health information among racial and ethnic groups in this country may necessitate the use of alternative channels and messages to provide health information that support and reinforce cultural norms, language preferences, literacy levels, and other values specific to unique cultural identities. ${ }^{16,27}$ The explosion of health information in the Internet has certainly opened pathways to disseminate health information. However, our research is consistent with prior research demonstrating that Web-based health information resources are not accessed equally by all. ${ }^{31,32}$ Given the low usage of the Internet among the Spanish-speaking HINTS respondents (79\% are not online) and the multiple barriers and frustrations experienced by these respondents in seeking cancer information both offline and online, it is clear that sociodemographic and cultural factors, including language, interact with and influence cancer information-seeking behaviors. Additionally, information source preferences and use among Hispanics, particularly recent immigrants and those with limited English proficiency, is an area that needs further examination.

Cancer information itself is complicated, as there are numerous recommendations related to prevention, screening, and treatment that are accompanied by a long list of medical terms related to specific types and stages of cancer. As new findings related to cancer prevention, screening, diagnosis, and treatment are covered by the media each day, the public is stimulated to stay up to date on the latest advancements and recommendations by searching for more detailed information. To effectively search for appropriate information, the public must be aware of and able to access information and education channels and sources; be able to choose credible sources that deliver appropriate and accurate information; and utilize negotiation, management, and comprehension skills to prioritize, process, and act on applicable information. ${ }^{27,33}$ These sources must be easily accessible and also provide information that is understandable and culturally competent, leaving the information seeker feeling confident in his or her ability to seek and find relevant information in the future. Findings from this study reveal this experience is compromised and frustrating for specific subgroups. For Hispanics, future studies should investigate the specific resources and channels used in searching for cancer information and identify where these resources, materials, and messages fall short in addressing the specific needs of this at-risk population. Only then can we begin to overcome the cancer information-seeking barriers of this 
heterogeneous population and contribute to the larger goal of eliminating communication inequities and cancer health disparities.

\section{References}

1. US Census Bureau. Table 4: Annual estimates of the Hispanic or Latino population by age and sex for the US: April 1, 2000 to July 1, 2006 (NC-EST2006-04-HISP). Release Date: May 17, 2007. Available at: http://www.census.gov

2. Timmins CL. The impact of language barriers on the health care of Latinos in the U.S.: a review of the literature and guidelines for practice. J Midwifery Womens Health. 2002; 47:80-96. [PubMed: 12019990]

3. Garbers, S.; Chiasson, MA. Inadequate functional health literacy in Spanish as a barrier to cervical cancer screening among immigrant Latinas in New York City. Prev Chronic Dis. 2004. Available at: http://www.cdc.gov/pcd/issues/2004/oct/03_0038.htm

4. Huerta EE. Cancer Statistics for Hispanics, 2003: good news, bad news, and the need for a health system paradigm change. CA Cancer J Clin. 2003; 53:205-207. [PubMed: 12924774]

5. Diaz VA. Cultural factors in preventive care: Latinos. Prim Cary Clin Office Pract. 2002; 29:503517.

6. American Cancer Society. Cancer Facts \& Figures for Hispanic/Latinos 2006-2008. Atlanta, GA: American Cancer Society; 2007.

7. McDougal JA, Madeleine MM, Daling JR, et al. Racial and ethnic disparities in cervical cancer incidence rates in the United States, 1992-2003. Cancer Causes Control. 2007; 18:1175-1186. [PubMed: 17805982]

8. Ramanadhan S, Viswanath K. Health and the information non-seeker: a profile. Health Commun. 2006; 20:131-139. [PubMed: 16965250]

9. Tichenor PJ, Donohue GA, Olien CN. Mass Media Flow and Differential Growth in Knowledge. Pub Opin Q. 1970; 34:159-170.

10. Viswanath, K.; Finnegan, JR, Jr. Knowledge gap hypothesis: Twenty five years later. In: Burleson, B., editor. Communication Yearbook. Vol. 19. Thousand Oaks, CA: Sage; 1996. p. 187-227.

11. Ku, L.; Waidmann, T. How race/ethnicity, immigration status, and language affect health insurance coverage, access to care and quality of care among the low-income population. Washington, DC: The Henry J. Kaiser Family Foundation; August. 2003 Available at: http://www.kff.org

12. Hudson JC, Watts E. Hispanic preferences for health care providers and health care information. Health Mark Q. 1996; 14:67-83. [PubMed: 10163026]

13. Gloria AM, Peregoy JJ. Counseling Latino alcohol and other substance users/abusers: cultural considerations for counselors. J Subst Abuse Treat. 1996; 13:119-126. [PubMed: 8880669]

14. Lehrer, J. Changing times: Ethnic media sector is growing. [Transcript of television broadcast]. PBS Newshour with Jim Lehrer. October 14. 2002 Available at: http://www.pbs.org/newshour/bb/media/july-dec02/ethnic_10-14.html

15. Talosig-Garcia M, Davis SW. Information-seeking behavior of minority breast cancer patients: an exploratory study. J Health Commun. 2005; 10(suppl 1):53-64. [PubMed: 16377600]

16. Cheong PH. Health communication resources for uninsured and insured Hispanics. Health Commun. 2007; 21:153-163. [PubMed: 17523861]

17. Fernandez LE, Morales A. Language and use of cancer screening services among border and nonborder Hispanic Texas women. Ethn Health. 2007; 12:245-263. [PubMed: 17454099]

18. Lara M, Gamboa C, Iya Kahramanian M, et al. Acculturation and Latino health in the U.S.: a review of the literature and its sociopolitical context. Annu Rev Public Health. 2005; 26:367-397. [PubMed: 15760294]

19. Scott SA, Jorgensen CM, Suarez L. Concerns and dilemmas of Hispanic AIDS information seekers: Spanish-speaking callers to the CDC national AIDS hotline. Health Educ Behav. 1998; 25:501-516. [PubMed: 9690107]

20. De Abla I, Sweningson JM. English proficiency and physicians' recommendation of Pap smears among Hispanics. Cancer Detect Prev. 2006; 30:292-296. [PubMed: 16844320] 
21. Jacobs EA, Karavolos K, Rathouz PJ, et al. Limited English proficiency and breast and cervical cancer screening in a multiethnic population. Am J of Public Health. 2005; 95:1410-1416. [PubMed: 16043670]

22. Shin, HB.; Bruno, R. Language use and English-speaking ability: 2000. US Census Bureau, Department of Commerce; October. 2003 Available at: http://www.census.gov/prod/2003pubs/c2kbr-29.pdf

23. US Census Bureau. US profile of selected social characteristics: 2000. Available at: http://www.census.gov

24. Office of Management and Budget. Revisions to the standards for the classification of federal data on race and ethnicity. Federal Register. 1997; 62:58781-58790.

25. RTI International. About SUDAAN. Available at: http://www.rti.org/sudaan

26. Freimuth V, Quinn SC. The contributions of health communication to eliminating health disparities. Am J of Public Health. 2004; 94:2053-2055. [PubMed: 15569949]

27. Vishwanath, K. Public communications and its role in reducing and eliminating health disparities. In: Thompson, GE.; Mitchell, F.; Williams, M., editors. Examining the Health Disparities Research Plan of the National Institutes of Health: Unfinished Business. Washington, DC: National Academies Press; 2006. p. 215-253.Appendix G

28. Tortolero-Luna G, Byrd T, Groff JY, Linares AC, Mullen PD, Cantor SB. Relationship between English language use and preferences for involvement in medical care among Hispanic women. $\mathrm{J}$ Womens Health. 2006; 15(6):774-85.

29. Nelson DE, Powell-Griner E, Town M, et al. A comparison of national estimates from the National Health Interview Survey and the Behavioral Risk Factor Surveillance System. Am J Public Health. 2003; 93:1335-1341. [PubMed: 12893624]

30. Oetzel J, De Vargas F, Ginossar T, Sanchez C. Hispanic women's preferences for breast health information: subjective cultural influences on source, message, and channel. Health Commun. 2007; 21:223-233. [PubMed: 17567254]

31. Lorence DP, Park H, Fox S. Racial disparities in health information access: resilience of the digital divide. J Med Syst. 2006; 30:241-249. [PubMed: 16978003]

32. Fox, S.; Livingston, G. Latinos Online. Washington, DC: Pew Hispanic Center/Pew Internet \& American Life Project; March 14. 2007 Available at: http://www.pewinternet.org

33. Brashers DE, Goldsmith DJ, Hsieh E. Information seeking and avoiding in health contexts. Human Commun Res. 2002; 28:258-271. 


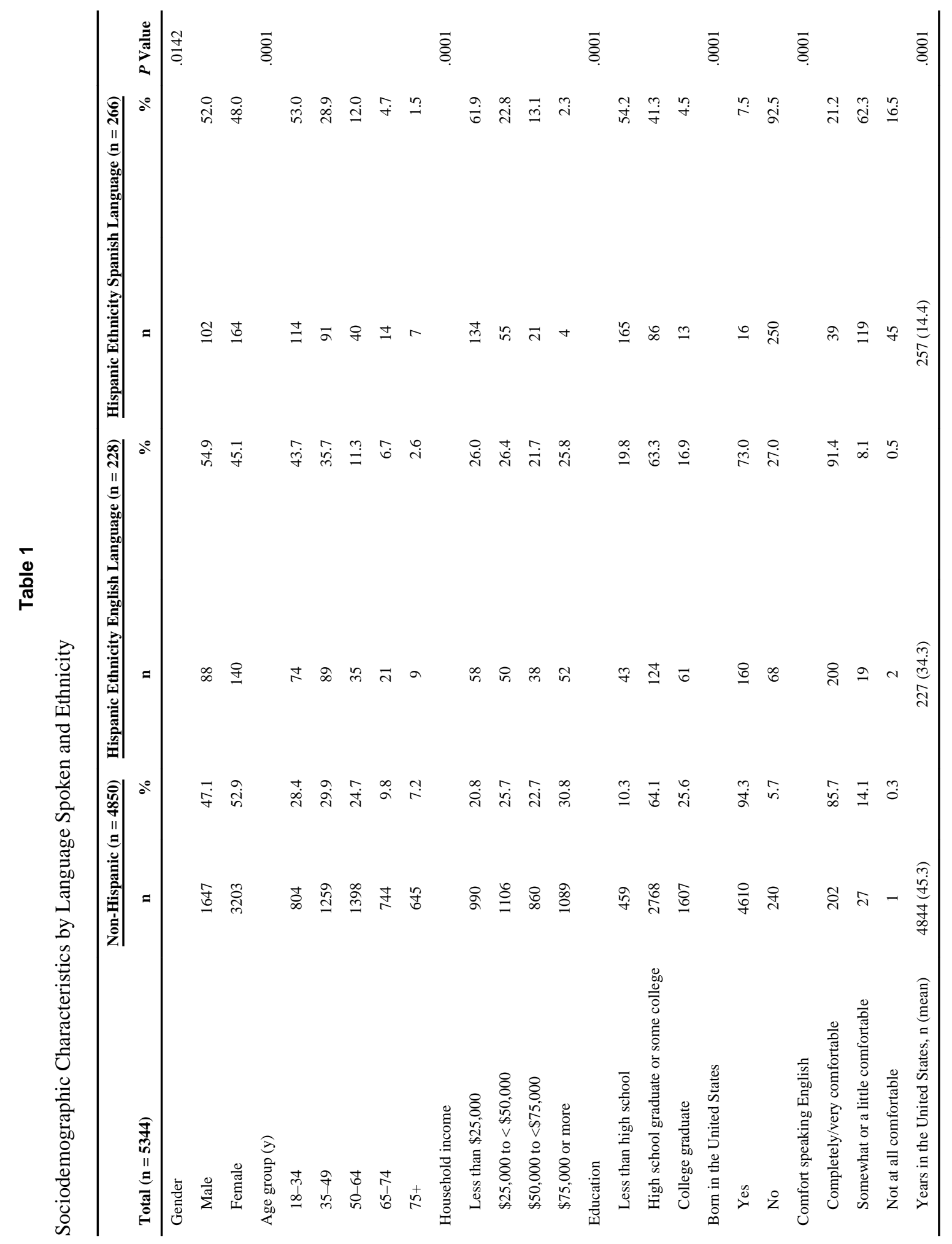




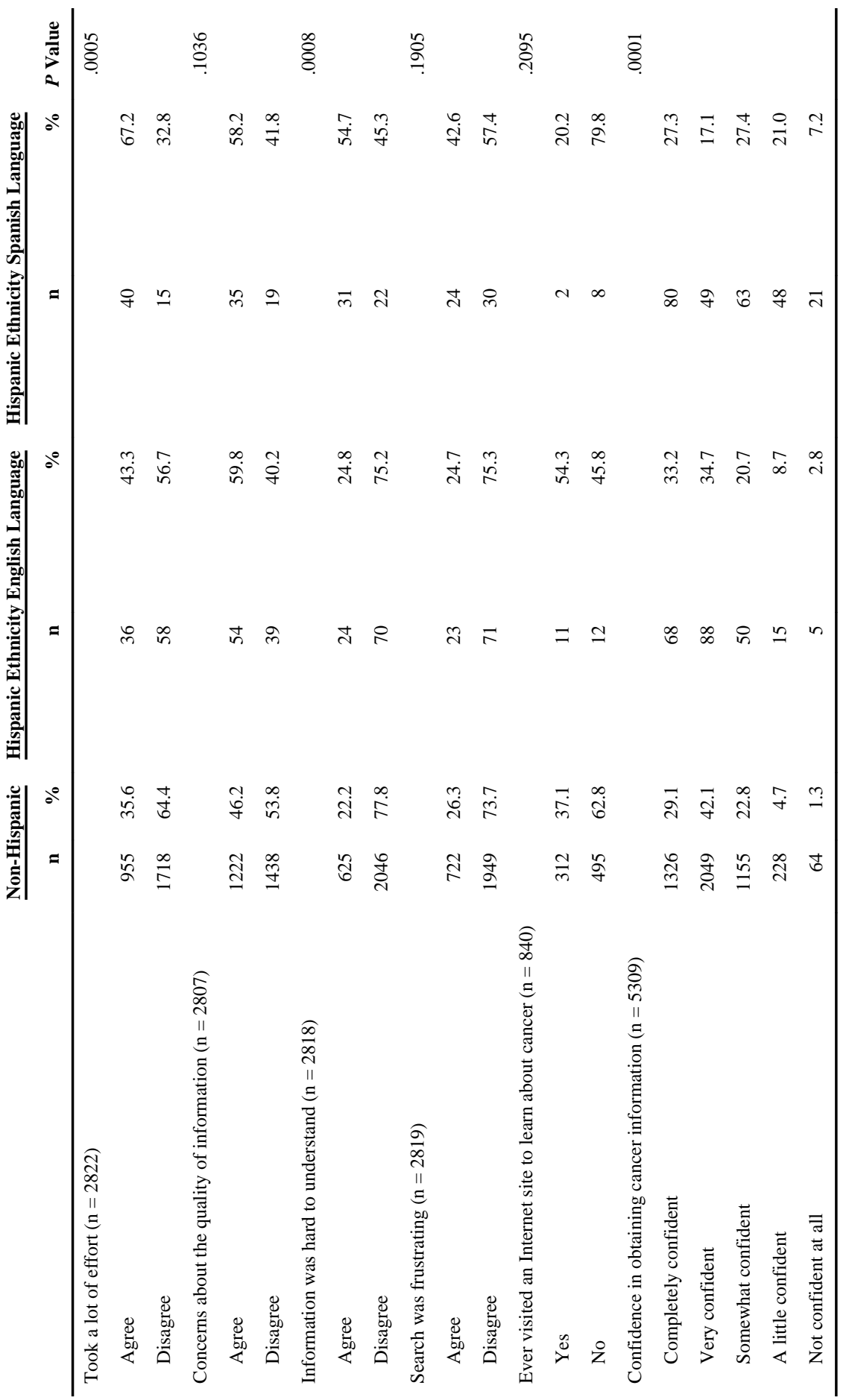


Table 3

Logistic Regression of Sociodemographic Characteristics onto Cancer Information Experiences*

\begin{tabular}{|c|c|c|c|c|}
\hline & Sought Cancer Information & $\begin{array}{l}\text { Confidence in } \\
\text { Obtaining } \\
\text { Information }\end{array}$ & Took a Lot of Effort & $\begin{array}{c}\text { Information Hard to } \\
\text { Understand }\end{array}$ \\
\hline \multicolumn{5}{|l|}{ Gender } \\
\hline Male & 1.00 & 1.00 & 1.00 & 1.00 \\
\hline Female & $1.79(1.46-2.20)$ & $1.17(0.95-1.44)$ & $0.92(0.66-1.27)$ & $0.89(0.68-1.15)$ \\
\hline \multicolumn{5}{|l|}{ Age group (y) } \\
\hline $18-34$ & 1.00 & 1.00 & 1.00 & 1.00 \\
\hline $35-49$ & $1.20(0.92-1.55)$ & $0.63(0.47-0.86)$ & $1.42(0.88-2.29)$ & $2.03(1.20-3.46)$ \\
\hline $50-64$ & $1.14(0.74-1.75)$ & $0.82(0.51-1.30)$ & $2.80(1.57-4.97)$ & $3.31(1.48-7.39)$ \\
\hline $65-74$ & $0.78(0.43-1.44)$ & $0.73(0.37-1.45)$ & $3.85(1.61-9.23)$ & 3.17 (1.03-9.73) \\
\hline $75+$ & $0.48(0.21-1.11)$ & $0.76(0.35-1.68)$ & $6.49(2.38-17.69)$ & $3.97(1.03-15.36)$ \\
\hline \multicolumn{5}{|l|}{ Education } \\
\hline Less than high school & 1.00 & 1.00 & 1.00 & 1.00 \\
\hline $\begin{array}{l}\text { High school graduate or some } \\
\text { college }\end{array}$ & $2.10(1.53-2.89)$ & $0.98(0.78-1.25)$ & $0.68(0.41-1.14)$ & $0.56(0.39-0.81)$ \\
\hline College graduate & $3.38(2.31-4.95)$ & $1.19(0.88-1.60)$ & $0.48(0.25-0.91)$ & $0.27(0.16-0.44)$ \\
\hline \multicolumn{5}{|l|}{ Household income } \\
\hline Less than $\$ 25,000$ & 1.00 & 1.00 & 1.00 & 1.00 \\
\hline$\$ 25,000$ to $<\$ 50,000$ & $1.04(0.81-1.35)$ & $1.09(0.83-1.43)$ & $0.86(0.59-1.25)$ & $0.75(0.52-1.08)$ \\
\hline$\$ 50,000$ to $<\$ 75,000$ & $1.09(0.84-1.40)$ & $1.40(1.01-1.94)$ & $0.68(0.44-1.05)$ & $0.63(0.42-0.93)$ \\
\hline$\$ 75,000$ or more & $1.22(0.94-1.59)$ & $1.63(1.21-2.19)$ & $0.65(0.42-1.00)$ & $0.54(0.34-0.86)$ \\
\hline \multicolumn{5}{|l|}{ Language of interview } \\
\hline Non-Hispanic & 1.00 & 1.00 & 1.00 & 1.00 \\
\hline Hispanic/Spanish Language & $0.25(0.15-0.43)$ & $0.35(0.22-0.57)$ & $2.56(0.94-6.95)$ & $2.35(0.92-6.01)$ \\
\hline Hispanic/English Language & $0.59(0.38-0.92)$ & $0.97(0.68-1.39)$ & $1.55(0.88-2.73)$ & $1.44(0.59-3.53)$ \\
\hline Years in the United States & $1.00(0.99-1.02)$ & $1.00(1.00-1.01)$ & $0.98(0.96-0.99)$ & $0.99(0.97-1.01)$ \\
\hline Model $\chi^{2}$ & $\chi_{14}^{2}=14.93 P<.0001$ & $\begin{aligned} & \chi^{2}{ }_{14}= 21.54 P<. \\
& 0001\end{aligned}$ & $\chi_{14}^{2}=9.48 P<.0001$ & $\chi^{2}{ }_{14}=37.90 P<.0001$ \\
\hline
\end{tabular}

*dds ratio (95\% Confidence Interval). 